\title{
An autoparasitoid wasp, inferior at resource exploitation, outcompetes primary parasitoids by using competitor females to produce males
}

\author{
ROSALINA MARRAO, ${ }^{1}$ ENRIC FRAGO, ${ }^{2}$ J J OSÉ A.PEREIR A ${ }^{1}$ \\ and A L E J A N D R O T E N A ${ }^{3}$ (D) ${ }^{1} \mathrm{CIMO} /$ Escola Superior Agrária, Instituto Politécnico de Bragança, Bragança, \\ Portugal, ${ }^{2}$ Centre de Biologie pour la Gestion des Populations, CIRAD, UMR CBGP, F-34398 Montpellier, France and ${ }^{3}$ Centro de \\ Protección Vegetal y Biotecnología, Instituto Valenciano de Investigaciones Agrarias, IVIA, Spain
}

\begin{abstract}
Autoparasitoids are intraguild consumers that attack and kill heterospecific and conspecific parasitoids as well as immature stages of hemipteran hosts, such as aphids, whiteflies and soft scales. Field experiments assessing the importance of interspecific competition between autoparasitoids and primary parasitoids, as well as its impact on herbivore suppression, are scarcely found in the ecological literature.

2. Using field data from 40 olive orchards, this study examined the mechanisms that regulate: (i) the interspecific competition between primary parasitoids of the genus Metaphycus and the autoparasitoid Coccophagus lycimnia; and (ii) the density of their shared herbivore host, the soft scale Saissetia oleae.

3. Metaphycus parasitoids used smaller hosts than C. lycimnia, yet did not outcompete C. lycimnia. On the other hand, C. lycimnia preferred to use Metaphycus females as secondary hosts for producing males rather than their own females. This preference might explain why the autoparasitoid negatively affected the density of the primary parasitoids.

4. Parasitism by the autoparasitoid C. lycimnia at the beginning of the season was the sole variable positively related to host mortality throughout the season, showing its greater effect on herbivore suppression.

5. In this study, an autoparasitoid, inferior at resource exploitation, was shown to outcompete a primary parasitoid without disrupting herbivore suppression.
\end{abstract}

Key words. Coccophagus, exploitative competition, interspecific competition, intraguild predation, Metaphycus, soft scales.

\section{Introduction}

Historically, attempts at biological control have often failed because they ignored the fact that natural enemies are part of a complex food web, where the top-down regulation of herbivore populations is the outcome of multiple species interacting at different trophic levels (Murdoch et al., 1985; Rosenheim et al., 1995; Rosenheim, 1998; Borer et al., 2003, 2004; Janssen et al., 2006; Boivin \& Brodeur, 2006; Tougeron \& Tena, 2019). A common interaction in these multitrophic food webs is intraguild predation, wherein one natural enemy consumes

Correspondence: Alejandro Tena, Centro de Protección Vegetal y Biotecnología, Instituto Valenciano de Investigaciones Agrarias (IVIA), Ctra CV-315, km 10.7. 46113, Moncada, Spain. E-mail: atena@ivia.es another. Numerous studies have suggested that intraguild predation weakens the top-down regulation of herbivores by natural enemies (May \& Hassell, 1981; Polis et al., 1989; Rosenheim et al., 1995; Rosenheim, 1998; Borer et al., 2003; Boivin \& Brodeur, 2006; Janssen et al., 2006). Hymenopteran parasitoids are often among the most important natural enemies of herbivores, but they are commonly victims rather than perpetrators of intraguild predation because their larvae are susceptible to consumption by competing predators that feed on the same herbivorous hosts (Rosenheim et al., 1995; Rosenheim, 1998; Snyder \& Ives, 2008; Frago, 2016). However, some species of parasitoids can also act as intraguild attackers. In some species, males develop as obligate hyperparasitoids of females of their own and other parasitoid species, whereas females develop as primary parasitoids of herbivores, i.e. autoparasitoid sensu 
(Hunter \& Woolley, 2001). Therefore, like intraguild predators, autoparasitoids can kill and consume both their competitors and their common hosts (Rosenheim et al., 1995).

The impacts of autoparasitoids in mediating the strength of top-down regulation of herbivores by their primary parasitoids sparked a lively debate in the literature of the 1990s and 2000s. A key question was whether any suppression of herbivore regulation caused by parasitism of primary parasitoids could be compensated by the autoparasitoids' direct parasitism on herbivorous hosts. From a theoretical perspective it is difficult to anticipate whether an autoparasitoid will cause an increase or decrease in long-term herbivore population densities when the main entomophagous arthropod is a primary parasitoid (Snyder $\&$ Ives, 2008). This is because, based on theory, the disruption of host suppression by the autoparasitoid requires moderately strong but not too strong attack rates on hosts parasitised by the primary parasitoid (Snyder \& Ives, 2008). Therefore, according to theoretical studies, the outcome of competition between primary parasitoids and autoparasitoids for host suppression variably falls between disruption and synergism.

Studies examining the effect of autoparasitoids on host suppression have reached divergent conclusions (Bográn et al., 2002; Hunter et al., 2002). These studies mostly comprised facultative autoparasitoids of the genus Encarsia (Hymenoptera: Aphelinidae) parasitising whiteflies (Hemiptera: Aleyrodidae) in field cages. Hunter et al. (2002) examined the interactions among the autoparasitoid Encarsia sophia $[=$ E. transvena (Timberlake)], the primary parasitoid Eretmocerus eremicus Rose and Zolnerowich (Hymenoptera: Aphelinidae) and their shared host, the sweet potato whitefly Bemisia tabaci (Gennadius) (Hemiptera: Aleyrodidae). The interference by the autoparasitoid reduced primary parasitoid density, but produced no concomitant disruption of host suppression. The results support theoretical predictions that no disruption should occur when both parasitoids are equally efficient and suggest that an autoparasitoid may be as efficient as a primary parasitoid in suppressing herbivore populations (Snyder \& Ives, 2008). Bográn et al. (2002) examined interactions among three parasitoids of the silverleaf whitefly Bemisia argentifolii Bellows and Perring (Hemiptera: Aleyrodidae): the autoparasitoid Encarsia pergandiella Howard and the primary parasitoids Eretmocerus mundus Mercet (Hymenoptera: Aphelinidae) and Encarsia formosa Gahan. Contrary to the previous example, the autoparasitoid E. pergandiella disrupted whitefly suppression. In addition, the study demonstrated that primary parasitoids could also reduce the population density of autoparasitoids through asymmetric exploitative competition, because the primary parasitoid E. mundus utilises younger developmental stages of the host than the autoparasitoid E. pergandiella. Mathematical simulations also predicted that parasitoid species attacking early host stages will always outcompete a parasitoid attacking later stages of the same host, unless the later attacking species is able to use previously parasitised hosts (Briggs, 1993). Briggs' (1993) theoretical predictions were partially supported by experimental work by Bográn et al. (2002) as the earlier host-stage-attacking $E$. mundus affected the population growth rates of both Encarsia species. While the previous field studies have contributed greatly to our understanding of the competition between primary parasitoids and autoparasitoids, their contribution to understanding the population dynamics of the insects involved lacked validation in natural scenarios because parasitoids were artificially released in cages, so their phenology and any effect of metapopulation structure, among other variables, were not considered (Janssen et al., 2006).

Coccophagus (Hymenoptera: Aphelinidae) is a common genus of autoparasitoids. Parasitoids of this genus have been widely used in several programmes of biological control against soft scale insects (Hemiptera: Coccidae) together with primary parasitoids of the Metaphycus (Hymenoptera: Encyrtidae) genus (Kapranas \& Tena, 2015). The latter are considered the main natural enemies of soft scales because unlike Coccophagus they are strictly primary parasitoid and can exploit smaller scales and hence can capitalise hosts through exploitative competition. However, it is unclear whether Coccophagus can negatively influence the population dynamics of Metaphycus and consequently the population density of soft scale insects (Kapranas \& Tena, 2015). Excessive hyperparasitism by Coccophagus lycimnia (Walker) (Hymenoptera: Aphelinidae) has been suggested as one factor preventing Metaphycus helvolus (Compere) (Hymenoptera: Encyrtidae) populations from building up as host density increased, resulting in poor control of Coccus pseudomagnoliarum (Kuwana) (Hemiptera: Coccidae) in Californian citrus (Bernal et al., 1998, 1999, 2001). However, later studies suggested that Coccophagus species could be efficient biological control agents of soft scale insect pests because they can reach greater population densities than Metaphycus (Schweizer et al., 2002, 2003). Similarly, an increase in Coccophagus parasitism on Coccus hesperidum L. (Hemiptera: Coccidae) did not lead to a reduction of parasitism by Metaphycus species (Kapranas et al., 2007). While these observations are based on field surveys, research on the role of interspecific competition between primary parasitoids and autoparasitoids on their own population dynamics and that of their shared coccid hosts is still lacking. These types of studies are needed to reconcile theory with extensive observations from agricultural systems.

Here, we report data on insects sampled at 40 olive orchards where several primary parasitoids of the Metaphycus genus and one autoparasitoid, C. lycimnia, coexist simultaneously and regulate the black scale Saissetia oleae (Olivier) (Hemiptera: Coccidae) (Pereira, 2004). These data were used to analyse the mechanisms that regulate the interspecific competition between primary parasitoids and an autoparasitoid, as well as whether this competition affects the density of their shared coccid host. Regarding the mechanisms, we first hypothesise that small hosts provide competition-free space for the primary parasitoids. Strong host exploitation by the facultative autoparasitoid species should, therefore, lead to a shift in the size of the hosts attacked by the primary parasitoids. More precisely, we hypothesise that Metaphycus should develop on smaller hosts under conditions of high host exploitation by the autoparasitoid C. lycimnia. Second, we (indirectly) tested whether $C$. lycimnia has a sex determination strategy that responds to the density of the primary parasitoids. In particular, we hypothesise that the adult (secondary) sex ratio of $C$. lycimnia will be increasingly male-biased as a 
higher percentage of hosts are exploited by primary parasitoids. Our study is novel because prior field studies did not examine the role of interspecific competition between primary parasitoids and an autoparasitoid, their population dynamics, and the population dynamics of their shared host.

\section{Materials and methods}

\section{Study system}

Saissetia oleae is a serious pest of citrus and olive in most regions of the world (Ben-Dov \& Hodgson, 1997). This pestiferous insect is oviparous and parthenogenetic. It has one annual generation, although in the studied region a second partial generation is possible in olive trees (Pereira, 2004; Tena et al., 2007). Eggs are laid at the end of spring and in autumn when the second generation occurs. The generations are highly synchronised (Tena et al., 2007). This species has three immature nymphal instars. The first instar, also known as the crawler, is mobile and is not attacked by parasitoids. The second and third instars are the predominant instars from September to May and they tend to settle on leaves (Pereira, 2004; Tena et al., 2007). There, they are attacked by a complex of parasitoids dominated by the genus Metaphycus and Coccophagus. Adults of coccid are attacked by the parasitoid Metaphycus lounsburyi (Howard) (Hymenoptera: Encyrtidae). Saissetia oleae oviposition occurs predominantly from the end of May to July, the eggs of which are attacked by the egg predator Scutellista caerulea (Fonscolombe) (Hymenoptera: Pteromalidae) (Pereira, 2004; Tena et al., 2008a).

Herein, we studied the interaction of the primary parasitoids of the Metaphycus genus and the autoparasitoid C. lycimnia when they parasitise the immature instars of $S$. oleae. The three species of Metaphycus [M. helvolus, M. flavus (Howard) and $M$. lounsburyi] were included in the research. The two former species are the main parasitoids of $S$. oleae nymphs in the Mediterranean region (Pereira, 2004; Tena et al., 2008a), whereas $M$. lounsburyi is often considered specific to adult scales, even though it has also been recovered from immature instars (Pereira, 2004; Tena et al., 2008a; Tena \& Garcia-Marí, 2009). The three species are facultatively gregarious endoparasitoids (generally a single egg is laid inside the host but not always), arrhenotokous (unfertilised eggs produce males and fertilised eggs produce females), and synovigenic (females emerge with at most a small fraction of their lifetime complement of mature eggs). In addition, M. helvolus and M. flavus exhibit destructive host-feeding; adults can kill their hosts for nutrition, not only use them for reproduction (Flanders, 1942; De Bach, 1943; Bernal et al., 1999; Kapranas \& Luck, 2008; Tena et al., 2008b). See Guerrieri and Noyes (2000) and Kapranas and Tena (2015) for more information on biology, taxonomy, and geographical distribution. Coccophagus lycimnia is an autoparasitoid whose males develop as obligate hyperparasitoids of both conspecific and heterospecific females, while females develop in immature $S$. oleae scales. This parasitoid is solitary, arrhenotokous, and can also host feed (Muegge \& Lambdin, 1989; Bernal et al., 2001).

\section{Orchards and experimental design}

To determine the intensity of the competition between the primary parasitoids of the Metaphycus genus and the autoparasitoid C. lycimnia and how this competition affects natural populations of their common host, S. oleae, 40 olive orchards with distinct host densities at the beginning of the season (September) were selected.

The 40 orchards were located in the olive-growing region of Trás-os-Montes, northeast Portugal (Fig. 1). The characteristics of the orchards are detailed in Appendix S1. Briefly, orchards had two soil cover types: bare soil by means of herbicide applications or tilling and natural ground vegetation. The planting pattern varied between $6 \times 6 \mathrm{~m}$ and $10 \times 10 \mathrm{~m}$. Olive trees were between 40 to 50 years old, were pruned every $2-3$ years, and were not irrigated. During the assay the orchards were under full commercial production without insecticide use.

\section{Sampling protocols}

Orchards were sampled in three periods (September and November 2011 and May 2012). These months were selected because the first nymphal parasitoids are often observed in September, and the highest parasitism rates occur from October to November, as well as from April to May (Pereira, 2004). At each sampling period and olive orchard, two twigs $(20 \mathrm{~cm}$ long) infested with $S$. oleae were collected in 10 randomly selected olive trees. Twigs were isolated in plastic bags and transported in ice chests to the laboratory where they were stored at $6{ }^{\circ} \mathrm{C}$ for later observation. Samples were processed within $48 \mathrm{~h}$ of collection.

Once in the laboratory, a subsample of 20 leaves per tree was obtained (10 leaves per twig) leading to a total of 200 leaves per orchard. Each subsample was observed under a stereomicroscope to assess the numbers of live and parasitised $S$. oleae specimens of each instar. Parasitised scales were recognised based on their colour as they become yellowish or black depending on whether they are parasitised by Metaphycus spp. or Coccophagus spp., respectively, as well as by the convex shape of the scale (Pereira, 2004; Tena et al., 2008a; Tena \& Garcia-Marí, 2008). To assess host size, the length of the major axis of all second and third nymphal instars (suitable for parasitism by Metaphycus flavus, M. helvolus and C. lycimnia) was measured to the nearest $0.01 \mathrm{~mm}$. Leaves bearing parasitised scales were individually introduced into a glass vial. Vials were sealed with a cotton plug and placed in a climatic chamber at $22^{\circ} \mathrm{C}, \mathrm{LD} 16: 8 \mathrm{~h}$ and $70 \% \mathrm{RH}$. Tubes were checked every 2 days for parasitoid emergence throughout the month following collection. At emergence, parasitoids were identified (Goulet \& Hulent, 1993; Guerrieri \& Noyes, 2000) and sexed.

\section{Statistical analyses}

In this study several linear models, mixed-effects models, and generalised mixed-effects models were constructed. All analyses were performed in R v.3.4.2 (R Development Team 

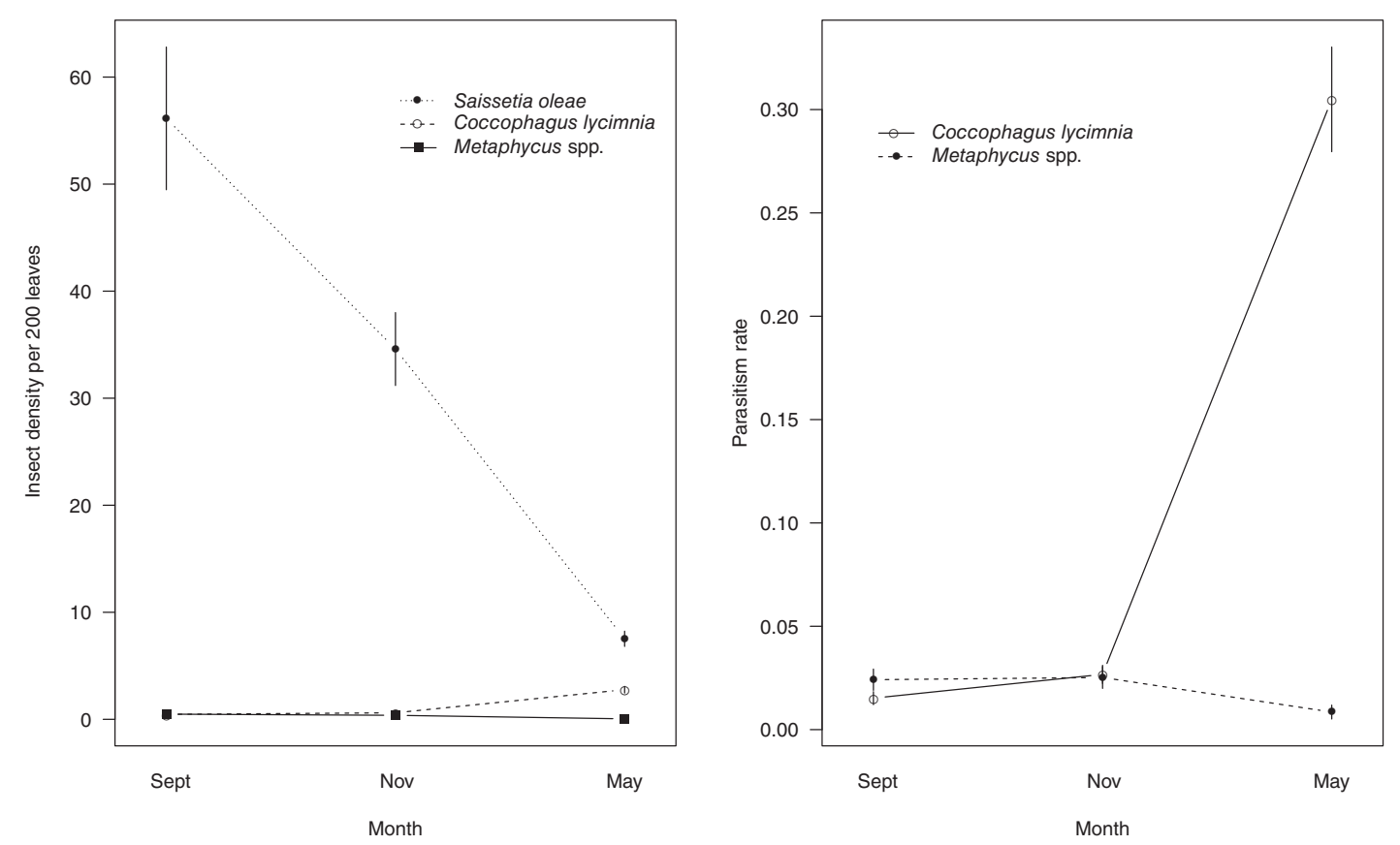

Fig. 1. Seasonal trend of Saissetia oleae, its parasitoids Coccophagus lycimnia and Metaphycus spp,. and parasitism by these parasitoids throughout the life cycle of the scale. (a) Number of S. oleae, C. lycimnia and Metaphycus spp.; (b) parasitism rate by C. lycimnia and Metaphycus spp. Data are means \pm SE.

2017). Linear models were fitted with the 'glm' function in the STATS package, whereas mixed-effects models and generalised mixed-effects models were fitted, respectively, with the 'lmer' and 'glmer' functions in the LME4 package (Bates et al., 2014). Mixed-effects models were fitted with a Gaussian error distribution, while generalised mixed-effects models had a binomial error distribution with a log-link function. In mixed-effects models, the region at which a given site belonged was included as a random factor to account for the spatial aggregation of sites within a given region. When several insects collected at the same sampling site were used as replicates, site nested within region was included as a random factor to account for both the non-independence of the hosts sampled at the same site, and the spatial aggregation of the sites within a region. In models that had more than one interaction term, non-significant interactions $(P>0.05)$ were removed. In all models, model fit was assessed by visual inspection of the residuals and with a $\chi^{2}$ goodness-of-fit test. In linear models the absence of data points with high influence was checked by calculating Cook's distances. In binomial mixed-effects models, model fit was further assessed with the DHARMA library through a simulation-based approach that creates scaled residuals from fitted generalised linear mixed models with the 'simulateResiduals' function in the DHARMA package. The overall uniformity of the residuals was then tested with a Kolmogorov-Smirnov goodness-of-fit test with the 'testSimulatedResiduals' function. All binomial mixed-effects models showed no sign of overdispersion, with dispersion factors $<1.2$. Significance of predictor variables (i.e. fixed terms) was usually reported with the 'summary' function in R. However, when categorical predictor variables had more than two different levels (this was the case when testing for seasonal or regional effects), overall significance was reported with likelihood ratio tests using the ANOVA function from the package CAR. This was done to simplify the presentation of results (expressed here as global ANOvA test). Posthoc tests in generalised mixed-effects models were performed with the 'glht' function in the MULTCOMP package using the Tukey multiple comparison procedure.

The following models were constructed in this study:

(i) The effect of parasitism on host mortality between months was tested with a mixed-effects model using a Gaussian error distribution with region included as the random factor. The response variable was defined as the difference in the number of live hosts between September and May [expressed as $\log ($ mortality +0.5$)]$, using as unit of replication the number of hosts in each site. Predictors were host exploitation by all Metaphycus, by C. lycimnia and their interaction. When exploring the effect of all Metaphycus species, a similar model was built but included host exploitation by each species and their interaction with C. lycimnia host exploitation.

(ii) Seasonal and regional patterns of $S$. oleae size and different sized hosts parasitised by Metaphycus species and $C$. lycimnia were tested with mixed-effects models using a Gaussian error distribution with site as random factor (region was not included as a random factor but as a fixed predictor). These models included insect size as the response variable and sampling month and region as predictors. In the models for parasitoid host size, the response variable was log-transformed. 
(iii) Partitioning of host resources by parasitoids was tested in a similar manner to a previous study (Pekas et al., 2016). The relationship between the size of available hosts and the size of parasitised hosts by each parasitoid species was analysed by two different methods. In the first, linear models were constructed including mean size of the parasitised hosts at a particular date and site as the response variable, and as predictors mean size of all scales sampled at a particular date and site as continuous, and parasitoid species as categorical. In the second, the Manly selectivity measure (Manly et al., 2002) was also estimated for each parasitoid species. This ratio was obtained by dividing the size of the hosts parasitised by the size of the hosts available at a particular date and site. A $t$-test was used to evaluate whether or not this ratio was different from 1. Significant results expressed how parasitoids used hosts that were bigger or smaller than the average in the environment. Data were not transformed, as the distribution of mean size values was normal. This was checked by plotting quantile-quantile plots.

(iv) Size-mediated interspecific parasitoid interactions were also tested, in a similar fashion to a previous study using generalised mixed-effects models with a binomial error distribution which included site nested within region as the random factor. As the response variable, each collected host was considered as either parasitised or not; host size and host exploitation by the competing parasitoids (and their interaction term between these variables) were included as predictors. For each parasitoid species and sampling month, a different model was built. In these models, the interaction terms between host size and host exploitation by the competing parasitoid tested our working hypotheses as they expressed whether parasitism on particular host sizes varied with the density of the competing parasitoid.

(v) Seasonal patterns of Metaphycus and C. lycimnia secondary sex ratio (emerged adults) were studied with mixed-effects models with a binomial error distribution that included site nested within region as the random factor. These models included the binomial factor that considered each parasitoid to be male or female as the response variable; the parasitoid identity, the sampling month, and their interactions were the predictors.

(vi) The effect of host size on parasitoid sex ratio was studied with mixed-effects models using a Gaussian error distribution with site nested within region as the random factor. These models included the size of the hosts parasitised [expressed as $\log (\operatorname{size}+0.5)$ ] as the response variable; parasitoid species, its sex, and their interaction were the predictors.

(vii) The effect of size-mediated interspecific parasitoid interactions on secondary sex ratio were studied with mixed-effects models with a binomial error distribution that included site nested within region as the random factor. These models were slightly overdispersed, and thus were corrected by including an observational-level random factor. For each parasitoid a different model was constructed, and hence the response variable was a binomial factor that considered each individual of a given parasitoid as male or female. The following predictors were included: host exploitation by both the tested parasitoid and the competing species and their pairwise interactions. A significant effect on host exploitation by the tested parasitoid would express density-dependent changes in host exploitation, whereas significant effects on host exploitation by the competing parasitoid would express changes in sex ratio associated to interspecific parasitoid interactions. Significant interaction between host size and host exploitation would indicate the mentioned effects varied with host size.

\section{Results}

Host abundance, parasitism rates, and interspecific parasitoid interactions

The first count of $S$. oleae scales was carried out in September, followed by further estimations of density in November and May. Population density decreased with time. The mean number of $S$. oleae scales and nymphs suitable for parasitism (second and third instar) markedly decreased from September to May (Fig. 1). Parasitism by Metaphycus species remained low throughout the seasons, whereas $C$. lycimnia parasitism peaked in May (Fig. 1).

The number of hosts that died between September and May was positively related to parasitism rates by $C$. lycimnia in September (mixed-effects model, $\beta=28.58, \quad t=2.79$, $n=33, P=0.0084)$, but not with parasitism rates by Metaphycus $(\beta=11.34, t=1.69, n=33, P=0.1)$. There was, however, a significant interaction between both parasitoid groups $(\beta=-563.78, t=-2.39, n=33, P=0.022)$; at low C. lycimnia parasitism, host mortality increased with Metaphycus parasitism in September, whereas at high C. lycimnia parasitism, host mortality tended to decrease with Metaphycus parasitism (Fig. 2a).

A more detailed model that considered parasitism rates by each of the three Metaphycus species individually was also built. After removing non-significant interactions, this model revealed that the number of hosts that died between September and May was positively related to parasitism rates by C. lycimnia (mixed-effects model, $\beta=31.05, t=3.11, n=31, P=0.0038$ ), but not to those by $M$. helvolus $(\beta=-25.43, t=-1.07$, $n=31, P=0.2909)$ or $M$. flavus $(\beta=3.36, t=0.39, n=31$, $P=0.6967)$. Metaphycus lounsburyi, however, had an effect on host mortality that depended on the parasitism of C. lycimnia, as revealed by a significant interaction between the rates of parasitism of these two species (M. lounsburyi parasitism, $\beta=24.69$, $t=2.02, n=31, P=0.0518$; interaction term, $\beta=-1020.49$, $t=-2.73, n=31, P=0.0106)$. This interaction shows that at low $C$. lycimnia parasitism, host mortality between September and May increased with M. lounsburyi parasitism in September, whereas at high C. lycimnia parasitism, host mortality tended to decrease with of M. lounsburyi parasitism (Fig. 2b). 

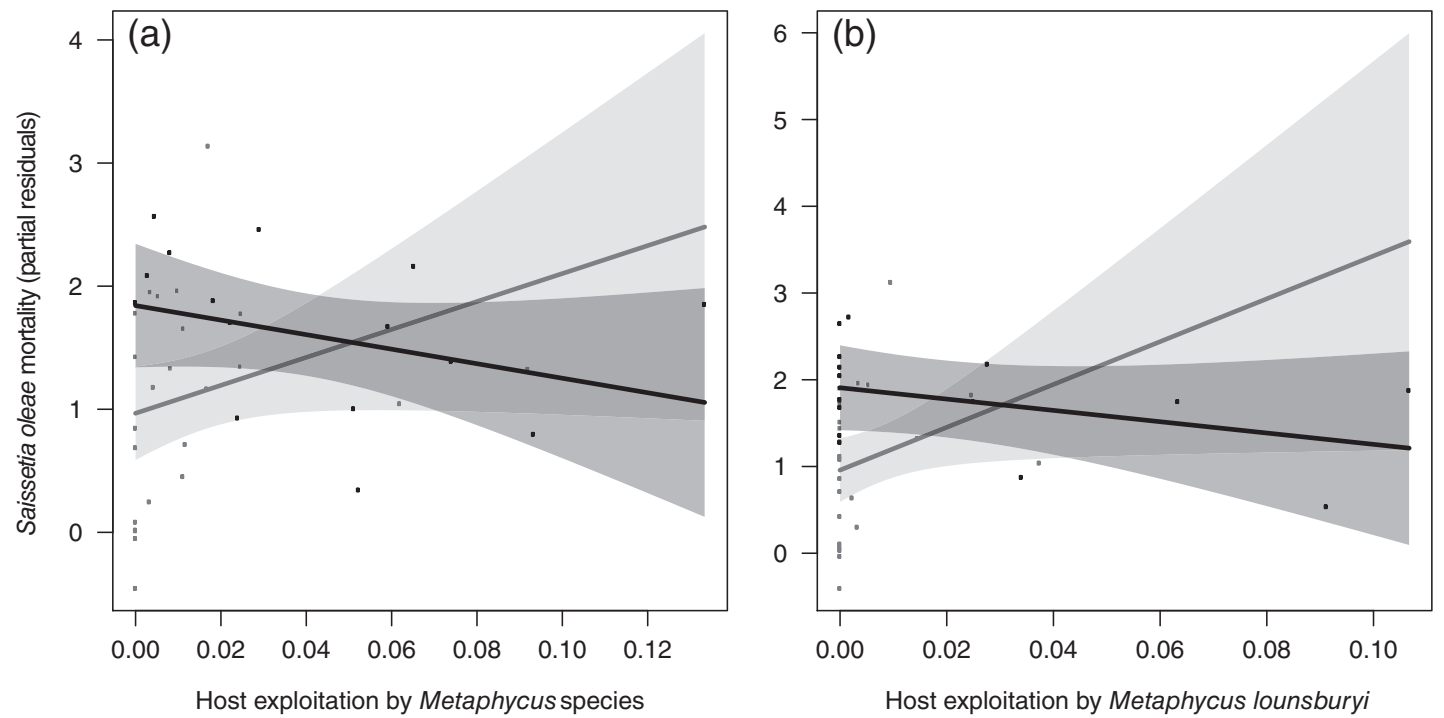

Fig. 2. (a, b) Effect of Coccophagus lycimnia and Metaphycus spp. (a) or Metaphycus lounsburyi parasitism (or host exploitation) (b) on the mortality of Saissetia oleae in September. Points represent model partial residuals and fitted lines; $95 \%$ confidence intervals are also estimated from the generalised mixed-effects models based on the VISREG package in R. The interaction represents high (dark grey) and low (light grey) host exploitation values by $C$. lycimnia based on the 50th quantile of this variable.

Seasonal and regional patterns of Saissetia oleae size and host sizes parasitised by Metaphycus and Coccophagus lycimnia

Considering $S$. oleae second and third instars together, mean insect size was significantly different among seasons (global ANOVA mixed-effects model, $\chi_{2}{ }^{2}=12.19, n=4287$, $P<0.0001)$. Overall, size differences among regions were not significant $\left(\chi_{5}{ }^{2}=3.63, n=4287, P=0.6034\right)$, but seasonal differences in scale size varied between regions as revealed by a significant interaction between season and region $\left(\chi_{10}^{2}=90.21\right.$, $n=4287, P<0.0001$; Appendix S1; Fig. 2). Overall scale size was $1.27 \pm 0.01 \mathrm{~mm}$ in September, $1.22 \pm 0.01 \mathrm{~mm}$ in November, and $1.57 \pm 0.01 \mathrm{~mm}$ in May; post hoc tests revealed scales to be significantly larger in May $(P<0.0001)$.

The hosts from where $C$. lycimnia was reared were significantly larger than those of Metaphycus (global ANOvA mixed-effects model for parasitoid genus, $\chi_{1}{ }^{2}=51.74$, $n=1209, P<0.0001)$. Differences were also significant among the three seasons: September, November and May (effect for season, $\left.\chi_{2}{ }^{2}=116.12, n=1209, P<0.0001\right)$. The seasonal effect was consistent between the two parasitoid genera as revealed by a non-significant interaction between these two fixed terms (interaction effect, $\chi_{2}{ }^{2}=1.47, n=1209, P=0.48$ ). When the Metaphycus species are considered separately, the size of the hosts from where the four parasitoids were reared differed significantly (mixed-effects model for parasitoid species, $\left.\chi_{3}{ }^{2}=53.19, n=1151, P<0.0001\right)$. Host size used by the four parasitoids also varied among seasons (mixed-effects model for season, $\left.\chi_{2}{ }^{2}=121.42, n=1151, P<0.0001\right)$, and the seasonal effect varied depending on the parasitoid species as revealed by a significant interaction $\left(\chi_{6}{ }^{2}=19.42, n=1151, P=0.0035\right.$; Fig. 3). Within this mixed-effects model, post hoc tests reveal that $C$. lycimnia hosts were significantly larger than hosts of $M$. flavus and M. lounsburyi $(P<0.05)$; however, they were not significantly different from $M$. helvolus hosts $(P>0.05)$. Among seasons, parasitised scales in May were significantly larger than those parasitised in September or November $(P<0.0001)$; scale size was not significantly different between September and November $(P=0.4445)$.

\section{Partitioning of host resources by parasitoids}

Considering the mean for each sampling date and study site, the size of parasitised scales by C. lycimnia and Metaphycus was significantly correlated with the mean size of hosts available in the scale population (li near model host size effect, $\beta=0.65, t=5.55, n=148, P<0.0001$ ) (Fig. 4a). In this model, parasitoid genus was also a significant explanatory variable. Hosts from where C. lycimnia was reared were larger than those of Metaphycus (linear model parasitoid effect with the Metaphycus genus as reference category, $\beta=0.39, t=2.04$, $n=148, P=0.043$ ). There was not a significant interaction between parasitoid species and host size, and hence the slope of the relationship between the size of the hosts available and those used did not depend on the parasitoid genus $(\beta=-0.16$, $t=-1.13, n=148, P=0.26$ ). If the different Metaphycus species are considered for each sampling date and study site, the mean size of scales parasitised by C. lycimnia, M. flavus, $M$. helvolus and $M$. lounsburyi was significantly correlated with the mean size of the hosts available in the population (linear model size effect, $\beta=0.48, t=5.41, n=168, P<0.0001$ ) (Fig. 4b). Relative to $C$. lycimnia (used in this model as the reference category), only $M$. lounsburyi used smaller hosts (linear model parasitoid effect for $M$. flavus, $\beta=-0.10, t=-0.42, n=168$, $P=0.68$; for $M$. helvolus, $\beta=-0.08, t=-0.28, n=168$, $P=0.79$; for $M$. lounsburyi, $\beta=-1.17, t=-4.23, n=168$, 
(a)

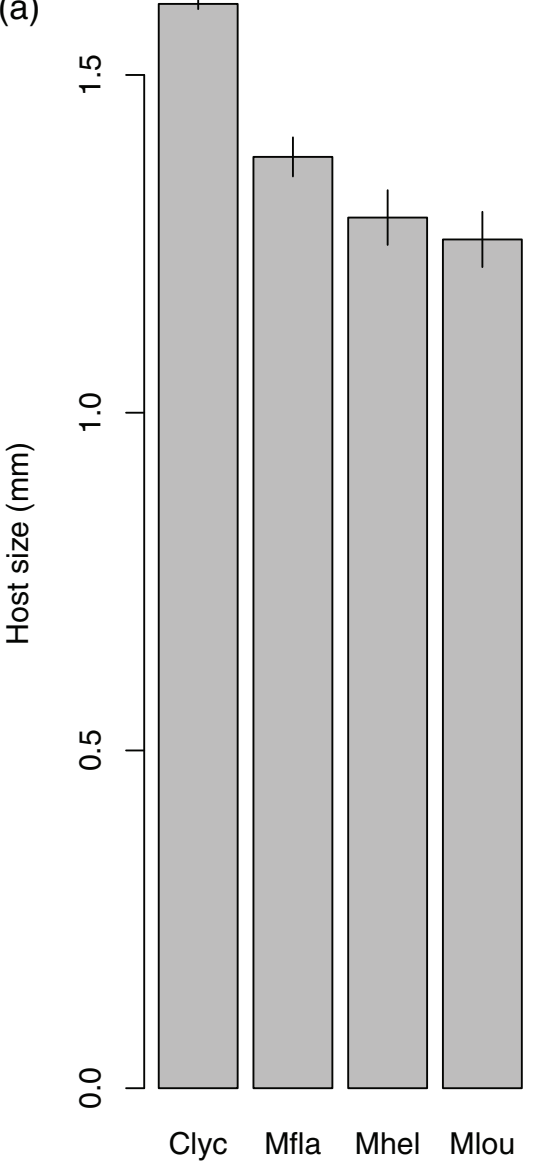

(b)

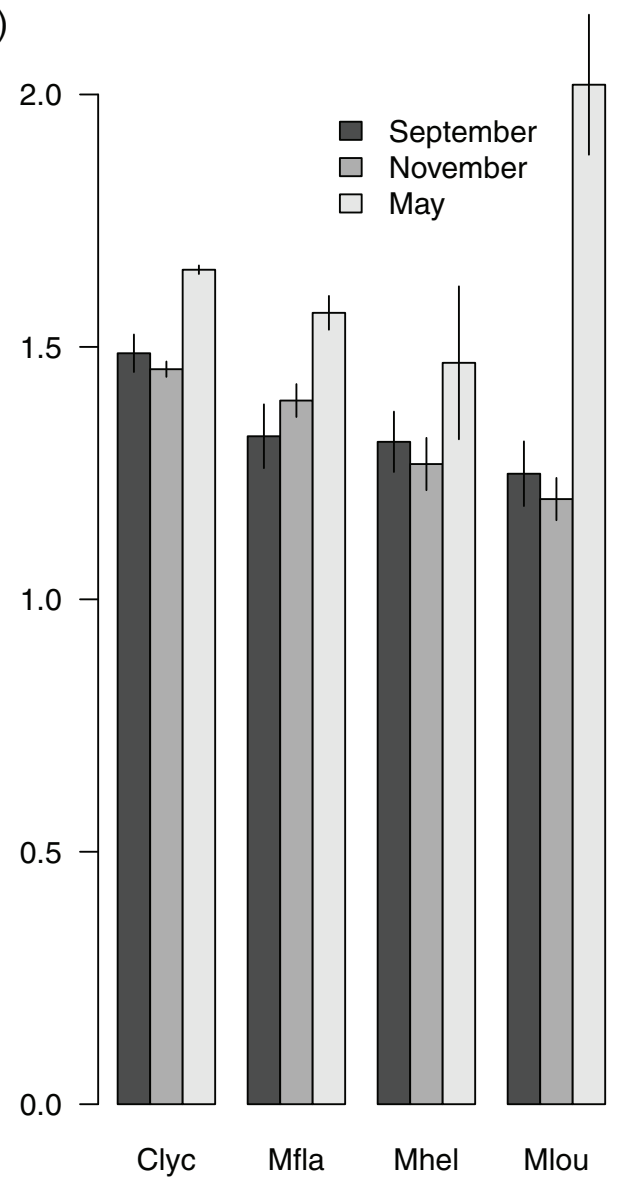

Fig. 3. (a, b) Size of Saissetia oleae (host size) (a) from which the parasitoids Coccophagus lycimnia (Clyc) and several species of Metaphycus [M. flavus (Mfla), M. helvolus (Mhel) and M. lounsburyi (Mhel)] emerged in different seasons (b).

$P<0.0001)$. Moreover, M. lounsburyi had a different host exploitation strategy from that of the other parasitoids. At large host sizes, it parasitised larger hosts than the other three parasitoids, whereas at smaller host sizes it parasitised smaller hosts (linear model interaction effect between host size and parasitism by $M$. flavus, $\beta=-0.03, t=-0.16, n=168, P=0.87$; by $M$. helvolus, $\beta=-0.10, t=-0.45, n=168, P=0.65$; by $M$. lounsburyi, $\beta=0.76, t=3.59, n=168, P=0.0004$ ) (Fig. 4b). The Manly selectivity measure revealed that both $C$. lycimnia and M. flavus, but not M. helvolus and M. lounsburyi, used hosts larger than the average found in the host population. Manly's ratio was significantly larger than the one in $C$. lycimnia $\left(1.13 \pm 0.02, t_{91}=8.05, P<0.0001\right)$ and $M$. flavus $\left(1.08 \pm 0.03, t_{39}=2.55, P=0.015\right)$, but did not differ from that in $M$. helvolus $\left(1.03 \pm 0.04, t_{16}=0.73, P=0.47\right)$ and $M$. lounsburyi $\left(1.02 \pm 0.03, t_{26}=0.61, P=0.54\right)$.

\section{Size-mediated interspecific parasitoid interactions}

The probability of parasitism was explored with mixed-effect models using a binomial error distribution which considered each host as either parasitised or not. When considering all
Metaphycus species together, C. lycimnia parasitism was positively related to host size in September, November and May, and positively related to Metaphycus host exploitation in May, but not in September and November (Table 1). These effects were consistent throughout Metaphycus host exploitation intensities in September and November, but not in May. In May, C. lycimnia parasitism was positively related to host size, but the slope of the correlation was lower at large host exploitation by Metaphycus, as revealed by a significant interaction between host size and host exploitation by Metaphycus. Thus host exploitation by Metaphycus had a negative effect on C. lycimnia parasitism through competition for larger hosts (Table 1; Fig. 5a). Parasitism by Metaphycus was related to host size in November only, and the interaction terms between host size and parasitism by $C$. lycimnia were never significant in these models (Table 1). Similar results were obtained when the Metaphycus species were analysed separately. Parasitism by C. lycimnia was always positively related to host size in the three sampling months when including host exploitation by any of the three Metaphycus species (Table 2). In the models that include host exploitation by $M$. flavus, none of the other variables were significant in any of the 3 months studied. In the models including host exploitation by $M$. helvolus, however, host exploitation by this 
(a)

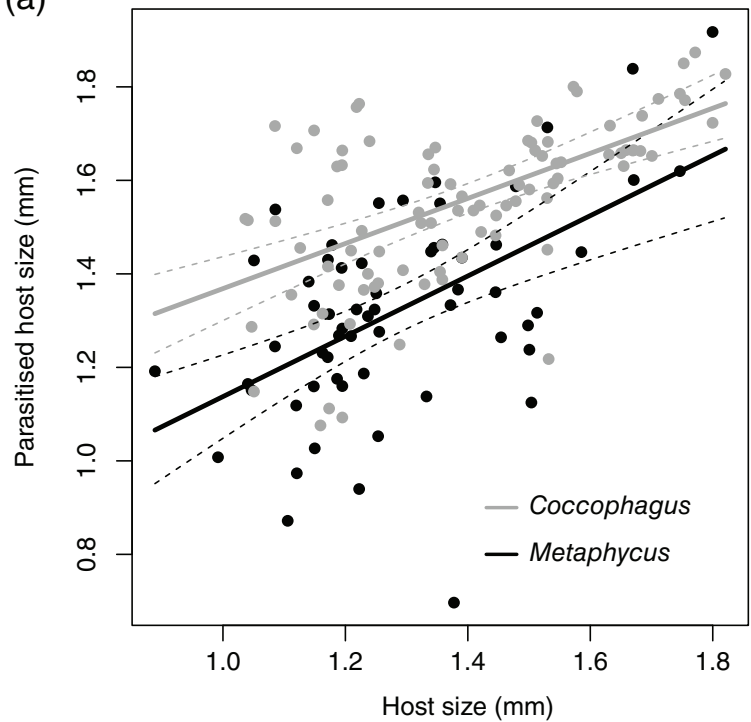

(b)

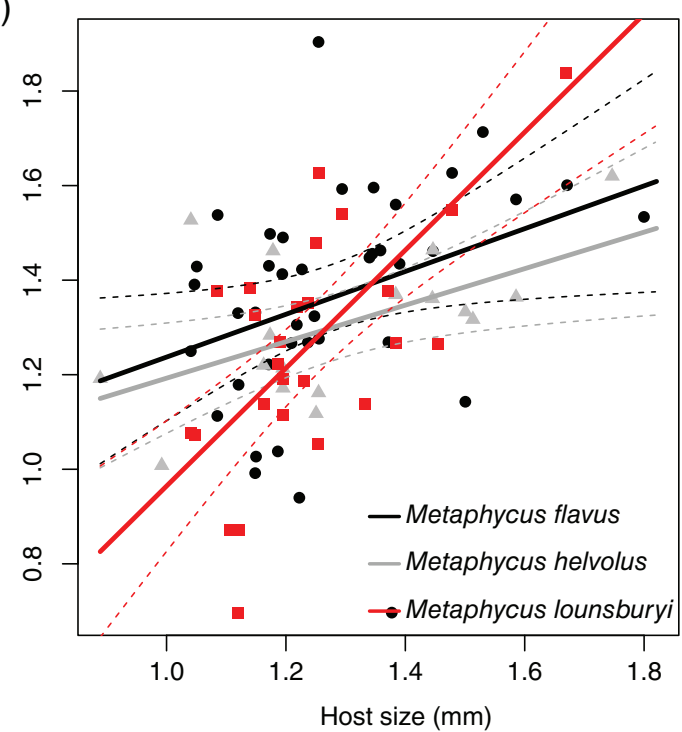

Fig. 4. (a, b) Relationship between the size of the hosts available and the size of the hosts attacked by Coccophagus lycimnia (light grey) and Metaphycus spp. (black) (a) and each Metaphycus species [M. flavus (black), M. helvolus (light grey) and M. lounsburyi (red)] (b) at each sampling date and orchard. Lines represent independent linear regression models with 95\% confidence intervals for each parasitoid.

Table 1. Effect of host size and host exploitation by the competing parasitoid on parasitism by the facultative autoparasitoid Coccophagus lycimnia and Metaphycus spp. on the soft scale Saissetia oleae.

\begin{tabular}{|c|c|c|c|c|c|c|c|c|c|}
\hline \multirow[b]{2}{*}{ Fixed factors } & \multicolumn{3}{|c|}{ September $(n=1323)$} & \multicolumn{3}{|c|}{ November $(n=1585)$} & \multicolumn{3}{|c|}{ May $(n=1284)$} \\
\hline & $\beta$ & $\mathrm{z}$ & $P$ & $\beta$ & $\mathrm{z}$ & $P$ & $\beta$ & $\mathrm{z}$ & $P$ \\
\hline \multicolumn{10}{|l|}{ Parasitism by $C$. lycimnia } \\
\hline Intercept & -6.8 & -6.278 & $<0.0001$ & -6.28 & -10.131 & $<0.001$ & -3.59 & -7.431 & $<0.0001$ \\
\hline Host size & 2.05 & 2.875 & 0.0041 & 3.12 & 7.633 & $<0.001$ & 2.53 & 9.446 & $<0.0001$ \\
\hline Metaphycus host exploitation & 1.86 & 0.086 & 0.9318 & -16.21 & -0.926 & 0.3552 & 44.07 & 2.538 & 0.0111 \\
\hline Host size $\times$ Metaphycus host exploitation & 8.21 & 0.555 & 0.5787 & 5.96 & 0.501 & 0.6179 & -28.22 & -3.168 & 0.0015 \\
\hline \multicolumn{10}{|l|}{ Parasitism by Metaphycus } \\
\hline Intercept & -4.3 & -4.089 & $<0.0001$ & -4.37 & -6.387 & $<0.001$ & -0.74 & -0.272 & 0.7853 \\
\hline Host size & 0.01 & 0.021 & 0.9832 & 1.01 & 2.159 & 0.0309 & -2.75 & -1.511 & 0.1311 \\
\hline C. lycimnia host explotation & 0.81 & 0.028 & 0.9772 & 2.35 & 0.157 & 0.8751 & -15.37 & -1.932 & 0.0534 \\
\hline Host size $\times C$. lycimnia host exploitation & 9.07 & 0.447 & 0.6553 & 1.57 & 0.141 & 0.8879 & 8.17 & 1.677 & 0.0936 \\
\hline
\end{tabular}

Cases of significant differences are shown in bold. The significant interactions are represented graphically in Fig. 3 .

parasitoid in September and May had a significant effect on C. lycimnia parasitism. This effect depended on host size but in different directions depending on the month. In September, the slope of the positive relationship between $C$. lycimnia parasitism and host size was smaller with large host exploitation by M. helvolus (Table 1; Fig. 5b), whereas the opposite was true in May (Table 1; Fig. 5c). In May, when the parasitoid M. lounsburyi had large host exploitation values, the slope of the positive correlation between $C$. lycimnia parasitism and host size was also smaller (Table 1; Fig. 5d).

Seasonal patterns of Metaphycus and Coccophagus lycimnia secondary sex ratio and effect of host size

The secondary sex ratio of $C$. lycimnia and of the different Metaphycus species was female-biased, particularly for
C. lycimnia: $92 \%$ of females in C. lycimnia, $60 \%$ in M. flavus, $55 \%$ in $M$. helvolus and $82 \%$ in M. lounsburyi. The proportion of females varied significantly between $C$. lycimnia and Metaphycus (global ANOVA mixed-effects model for parasitoid genus, $\left.\chi_{1}{ }^{2}=33.06, n=1285, P<0.0001\right)$ and between months (effect for season, $\chi_{2}{ }^{2}=48.39, n=1285, P<0.0001$ ); these differences also depended on the parasitoid genus (interaction effect, $\left.\chi_{2}{ }^{2}=18.25, n=1285, P=0.0001\right)$. A mixed-effects model that included all Metaphycus species revealed that both parasitoid species (global ANOVA mixed-effects model for parasitoid species, $\left.\chi_{1}^{2}=54.45, n=1285, P<0.0001\right)$ and sampling month (effect for season, $\chi_{2}{ }^{2}=46.67, n=1285, P<0.0001$ ) had a significant effect on secondary sex ratio, while the seasonal effect depended on the parasitoid species (interaction effect, $\left.\chi_{2}{ }^{2}=22.51, n=1285, P=0.0009\right)$. In simpler models limited to each parasitoid species, the proportion of $C$. lycimnia females 
(a)

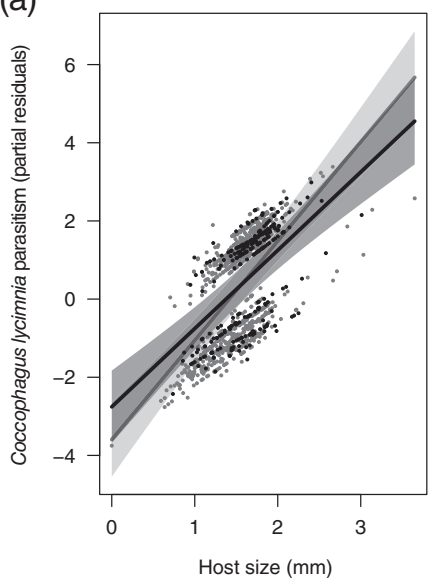

(b)

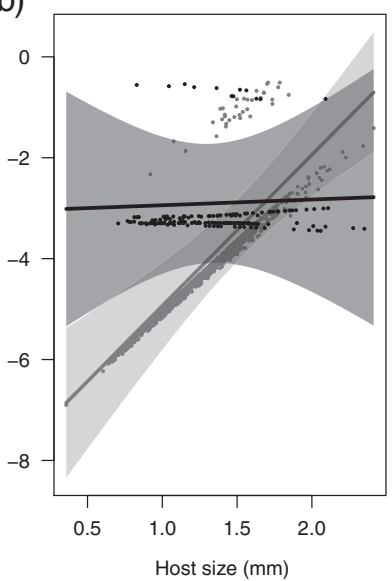

(c)

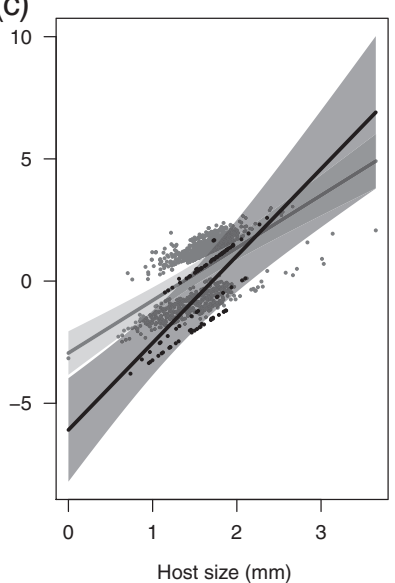

(d)

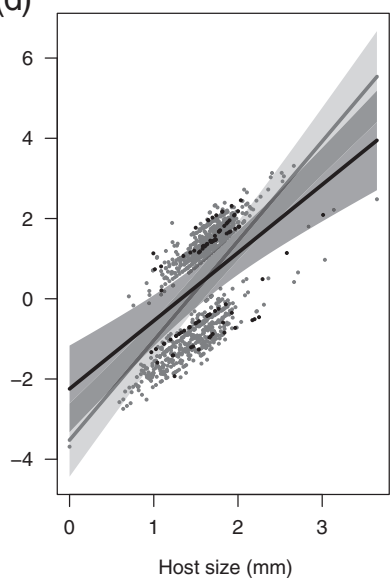

Fig. 5. Effect of Saissetia oleae size (host size) on Coccophagus lycimnia parasitism and its interaction with host exploitation by different Metaphycus species: (a) Metaphycus spp. in May; (b) M. helvolus in September; (c) M. helvolus in May; and (d) M. lounsburyi in May. Points represent model partial residuals and fitted lines; 95\% confidence intervals are also estimated from the generalised mixed-effects models based on the vISREG package in R. The interaction represents high (dark grey) and low (light grey) host exploitation values by Metaphycus based on the 50th quantile of this variable.

Table 2. Effect of host size and host exploitation by the competing parasitoid on parasitism by the facultative autoparasitoid Coccophagus lycimnia and three species of the genus Metaphycus on the soft scale Saissetia oleae.

\begin{tabular}{|c|c|c|c|c|c|c|c|c|c|}
\hline \multirow[b]{2}{*}{ Fixed factors } & \multicolumn{3}{|c|}{ September $(n=1323)$} & \multicolumn{3}{|c|}{ November $(n=1585)$} & \multicolumn{3}{|c|}{ May $(n=1284)$} \\
\hline & $\beta$ & $\mathrm{z}$ & $P$ & $\beta$ & $\mathrm{z}$ & $P$ & $\beta$ & z & $P$ \\
\hline \multicolumn{10}{|l|}{ Parasitism by $C$. lycimnia } \\
\hline Intercept & -6.98 & -7.154 & $<0.0001$ & -6.52 & -10.651 & $<0.0001$ & -3.30 & -7.093 & $<0.0001$ \\
\hline Host size & 2.29 & 3.631 & 0.0002 & 3.24 & 8.080 & $<0.0001$ & 2.32 & 8.962 & $<0.0001$ \\
\hline M. flavus host exploitation & 9.65 & 0.239 & 0.8107 & -14.56 & -0.409 & 0.6830 & 45.91 & 0.993 & 0.3210 \\
\hline Host size $\times M$. flavus host exploitation & 3.15 & 0.117 & 0.9066 & 2.44 & 0.102 & 0.9190 & -26.01 & -1.014 & 0.3110 \\
\hline Intercept & -7.93 & -8.774 & $<0.0001$ & -6.71 & -12.110 & $<0.0001$ & -2.95 & -6.470 & $<0.0001$ \\
\hline Host size & 2.99 & 5.353 & $<0.0001$ & 3.46 & 9.534 & $<0.0001$ & 2.15 & 8.607 & $<0.0001$ \\
\hline M. helvolus host exploitation & 256.61 & 3.345 & 0.0008 & 12.82 & 0.247 & 0.8050 & -165.59 & -2.764 & 0.0057 \\
\hline Host size $\times M$. helvolus host exploitation & -151.66 & -2.863 & 0.0042 & -34.45 & -1.016 & 0.3090 & 74.16 & 2.090 & 0.0367 \\
\hline Intercept & -6.49 & -6.597 & $<0.0001$ & -6.23 & -11.506 & $<0.0001$ & -3.52 & -7.576 & $<0.0001$ \\
\hline Host size & 1.91 & 3.169 & 0.0015 & 2.96 & 8.551 & $<0.0001$ & 2.48 & 9.591 & $<0.0001$ \\
\hline M. lounsburyi host exploitation & -26.22 & -0.831 & 0.4059 & -62.77 & -1.811 & 0.0701 & 67.18 & 3.011 & 0.0026 \\
\hline Host size $\times$ M. lounsburyi host exploitation & 30.50 & 1.432 & 0.1522 & 44.33 & 1.898 & 0.0576 & -41.32 & -3.583 & 0.0003 \\
\hline \multicolumn{10}{|l|}{ Parasitism by $M$. flavus } \\
\hline Intercept & -5.04 & -3.606 & 0.0003 & -6.45 & -6.160 & $<0.0001$ & -6.92 & -0.527 & 0.5980 \\
\hline Host size & 0.38 & 0.371 & 0.7103 & 1.97 & 2.764 & 0.0057 & -1.96 & -0.224 & 0.8230 \\
\hline C. lycimnia host exploitation & 15.70 & 0.381 & 0.7029 & 7.02 & 0.276 & 0.7828 & 2.75 & 0.110 & 0.9120 \\
\hline Host size $\times C$. lycimnia host exploitation & 2.51 & 0.086 & 0.9311 & -1.83 & -0.101 & 0.9193 & 3.30 & 0.198 & 0.8430 \\
\hline \multicolumn{10}{|l|}{ Parasitism by $M$. helvolus } \\
\hline Intercept & -19.98 & -2.354 & 0.0185 & -4.80 & -3.585 & 0.0003 & -1.64 & -0.369 & 0.7120 \\
\hline Host size & 5.49 & 1.279 & 0.2008 & -0.07 & -0.071 & 0.9434 & -1.57 & -0.512 & 0.6090 \\
\hline C. lycimnia host exploitation & 207.18 & 1.345 & 0.1787 & -24.64 & -0.689 & 0.4909 & -21.81 & -0.836 & 0.4030 \\
\hline Host size $\times$ C. lycimnia host exploitation & -102.57 & -0.990 & 0.3221 & 11.80 & 0.456 & 0.6487 & 6.48 & 0.406 & 0.6850 \\
\hline \multicolumn{10}{|l|}{ Parasitism by $M$. lounsburyi } \\
\hline Intercept & -6.35 & -1.527 & 0.1271 & -6.18 & -3.688 & 0.0002 & -14.76 & -1.041 & 0.2980 \\
\hline Host size & -0.86 & -0.839 & 0.4010 & 0.20 & 0.260 & 0.7948 & 1.68 & 0.240 & 0.8100 \\
\hline C. lycimnia host exploitation & -51.31 & -1.071 & 0.2850 & 7.07 & 0.305 & 0.7602 & 1.32 & 0.042 & 0.9660 \\
\hline Host size $\times$ C. lycimnia host exploitation & 31.11 & 0.963 & 0.3360 & -3.26 & -0.171 & 0.8645 & 1.14 & 0.073 & 0.9420 \\
\hline
\end{tabular}

Cases of significant differences are shown in bold. The significant interactions are represented graphically in Fig. 5. 


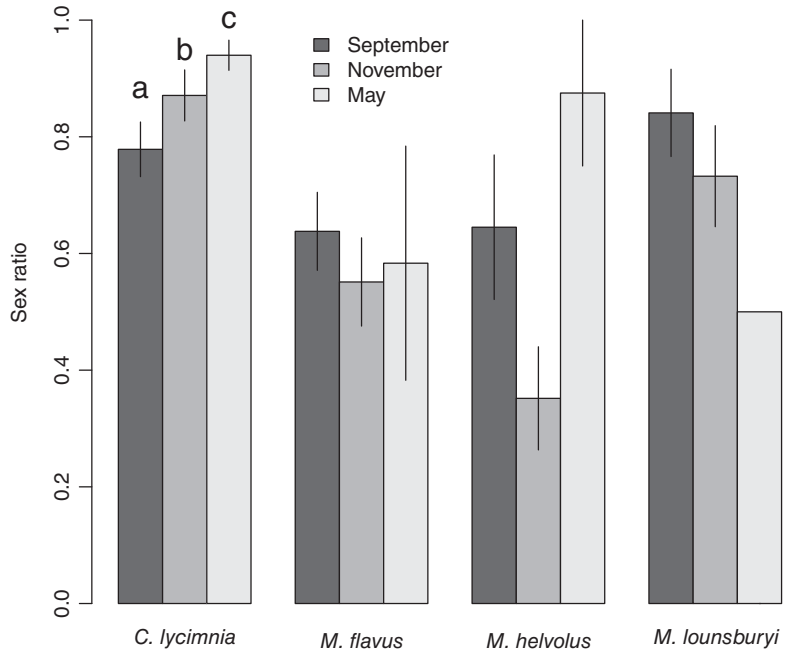

Fig. 6. Sex ratio (mean \pm SE) and host size of the different parasitoids studied: the autoparasitoid Coccophagus lycimnia and the primary parasitoids Metaphycus flavus, Metaphycus helvolus and Metaphycus lounsburyi on different seasons. Different letters denote significant differences among seasons. $P$-values were considered significant after Bonferroni correction $(P<0.05)$.

was larger in May than in September (post hoc tests in Fig. 6), whereas these differences were not significant for $M$. flavus, $M$. helvolus and M. lounsburyi $(P>0.2$; Fig. 6).

When considering all Metaphycus species together, the size of the hosts from where $C$. lycimnia emerged were significantly larger than those from where Metaphycus emerged (mixed-effects model for parasitoid species, $\beta=-0.15$, $t=-12.03, n=1146, P<0.0001)$. In addition, females of C. lycimnia, but not of Metaphycus, emerged from larger hosts than did males (mixed-effects model for parasitoid species, $\beta=-0.05, t=-3.25, n=1146, P=0.0012$; interaction effect between parasitoid species and secondary sex ratio, $\beta=0.05, t=2.16, n=1146, P=0.031)$. Results were slightly different when the different Metaphycus species were considered. As already shown in the previous analysis, $M$. flavus, M. helvolus and M. lounsburyi used smaller hosts than $C$. lycimnia (mixed-effects model for parasitoid species: M. flavus, $\beta=-0.11, t=-5.76, n=1146, P<0.0001 ; M$. helvolus, $\beta=-0.14, \quad t=-5.21, n=1146, \quad P<0.0001 ; M$. lounsburyi, $\quad \beta=-0.19, \quad t=-10.37, \quad n=1146, \quad P<0.0001)$; males also emerged from smaller hosts $(\beta=-0.06, t=-3.93$, $n=1146, P<0.0001$ ) (Appendix S1; Fig. 3). The interaction between secondary sex ratio and parasitoid species, however, was only significant for $M$. lounsburyi; in this species, females emerged from smaller hosts than did males. This interaction was not evident for either $M$. flavus or M. helvolus (interaction effect between secondary sex ratio and $M$. flavus, $\beta=0.04$, $t=1.24, n=1146, P=0.2150 ; M$. helvolus, $\beta=0.03, t=0.63$, $n=1146, P=0.5285 ; M$. lounsburyi, $\beta=2.51, t=-10.37$, $n=1146, P=0.0121)$.

\section{Effect of size-mediated interspecific parasitoid interactions on secondary sex ratio}

The probability of producing a female was explored with mixed-effect models using a binomial error distribution that considered each parasitoid as either female or male. For each sampling period, a different model was constructed to test specific hypotheses based on the included fixed factors and interactions among them. These analyses revealed that in September none of the variables included had a significant effect on female production for any parasitoid (Table 3 ). In November, the density of Metaphycus parasitoids had a positive effect on the production of $C$. lycimnia females. This result suggests that C. lycimnia may have a secondary sex ratio that is mediated by antagonistic interactions. In addition, this response depended on host size as revealed by a significant interaction between host size and Metaphycus host exploitation. The proportion of $C$. lycimnia females was positively related to host size but only at low levels of host exploitation by Metaphycus (Table 3; Fig. 7a). In May, at low $C$. lycimnia densities, the relationship between host size and secondary sex ratio was not evident; however,

Table 3. Effect of host size and host exploitation on the secondary sex ratio of the facultative autoparasitoid Coccophagus lycimnia and Metaphycus spp. when they parasitise the soft scale Saissetia oleae.

\begin{tabular}{|c|c|c|c|c|c|c|c|c|c|}
\hline \multirow[b]{2}{*}{ Fixed factors } & \multicolumn{3}{|c|}{ September $(n=1323)$} & \multicolumn{3}{|c|}{ November $(n=1585)$} & \multicolumn{3}{|c|}{ May $(n=1284)$} \\
\hline & $\beta$ & $\mathrm{z}$ & $P$ & $\beta$ & $\mathrm{z}$ & $P$ & $\beta$ & $\mathrm{z}$ & $P$ \\
\hline \multicolumn{10}{|l|}{ C. lycimnia probability of female } \\
\hline Intercept & 5.42 & 1.377 & 0.1690 & -8.70 & -2.456 & 0.0140 & -7.21 & -2.242 & 0.0249 \\
\hline Host size & -5.11 & -1.563 & 0.1180 & 3.85 & 1.765 & 0.0775 & 2.45 & 1.292 & 0.1964 \\
\hline Metaphycus host exploitation & 2.87 & 0.246 & 0.8060 & 221.21 & 2.072 & 0.0383 & 10.37 & 1.421 & 0.1553 \\
\hline C. lycimnia host exploitation & 24.88 & 1.155 & 0.2480 & -3.36 & -0.224 & 0.8231 & 14.10 & 1.966 & 0.0493 \\
\hline Size $\times$ Metaphycus host exploitation & & & & -141.84 & -1.979 & 0.0478 & & & \\
\hline Size $\times C$. lycimnia host exploitation & & & & & & & -8.77 & -2.001 & 0.0454 \\
\hline \multicolumn{10}{|l|}{ Metaphycus probability of female } \\
\hline Intercept & 0.44 & 0.237 & 0.8130 & -1.44 & -1.278 & 0.2010 & NA & NA & NA \\
\hline Host size & -0.99 & -0.654 & 0.5130 & 0.50 & 0.639 & 0.5230 & NA & NA & NA \\
\hline Metaphycus host exploitation & -8.49 & -0.809 & 0.4190 & 3.12 & 0.818 & 0.4130 & NA & NA & NA \\
\hline C. lycimnia host exploitation & 0.45 & 0.023 & 0.9820 & 2.47 & 0.368 & 0.7130 & NA & NA & NA \\
\hline
\end{tabular}

Cases of significant differences are shown in bold. The significant interactions are represented graphically in Fig. 7. 
(a)

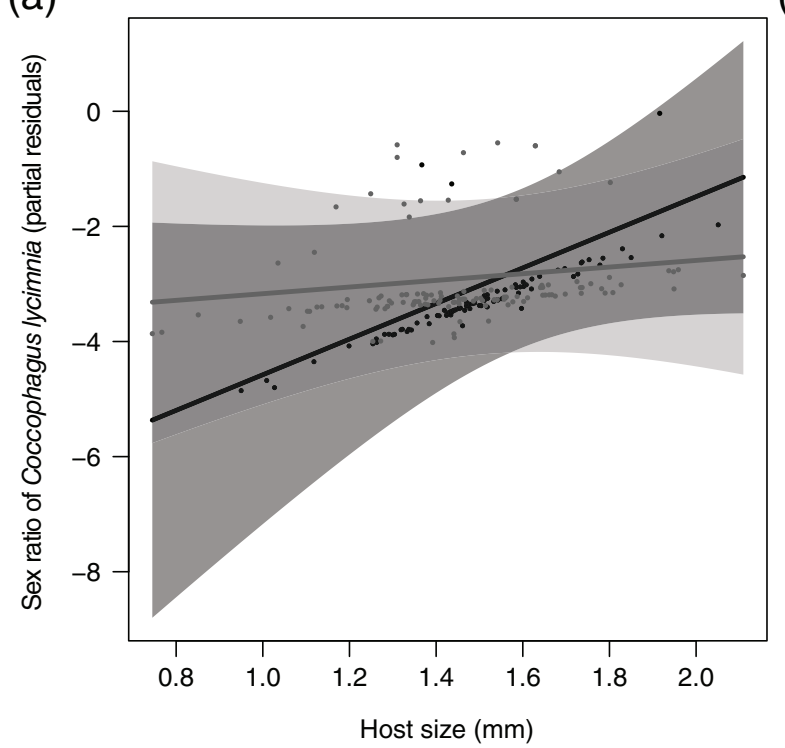

(b)

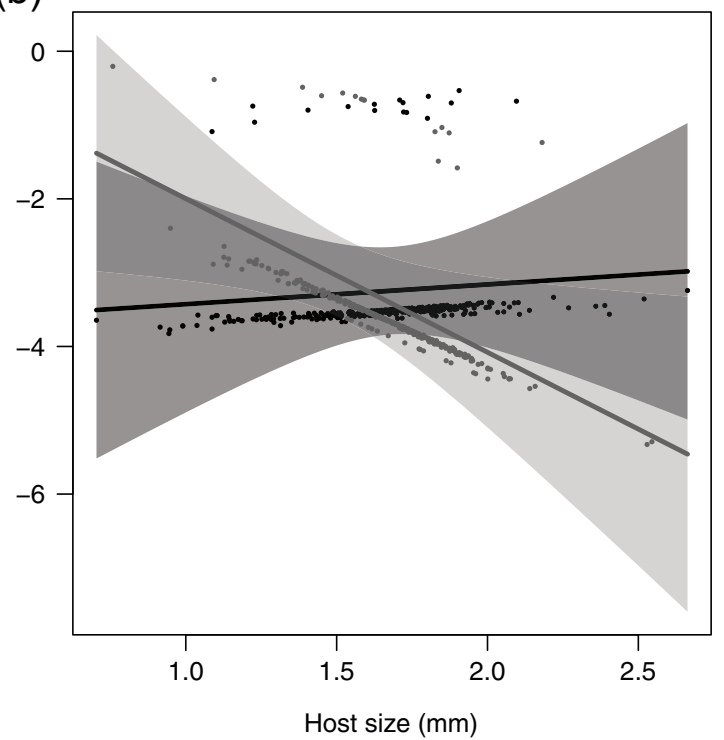

Fig. 7. (a, b) Effect of the interaction between Metaphycus spp. parasitism and Saissetia oleae size on the secondary sex ratio of Coccophagus lycimnia in November (a) and May (b). The fitted lines were estimated from the generalised mixed-effects models, and the points represent the partial residuals of the models based on the VISREG package in R. The interaction represents high (dark grey) and low (light grey) host exploitation values by Metaphycus based on the 50th quantile of this variable.

this relationship was negative at high $C$. lycimnia densities. As C. lycimnia males can be produced via facultative hyperparasitism of its own females (autoparasitism), it is likely that high C. lycimnia densities promote this behaviour; hence the number of males in large hosts was increased (Fig. 7b). The production of Metaphycus females was not altered by either host size or antagonistic interactions. Due to a low number of insects obtained, however, we were not able to test these effects in May (Table 3).

\section{Discussion}

Our study reports a case of competition between primary parasitoids and an autoparasitoid attacking a common host, along with the effect of this competition on host suppression under field conditions. Our results suggest that an autoparasitoid, although an inferior exploitative competitor (i.e. it attacks common hosts later in their development than the primary parasitoid), can outcompete the primary parasitoid without disrupting the suppression of their common host. Even though theoretical studies suggest that this should be the case in most scenarios, there is currently little evidence of this outcome, particularly under field conditions.

Coccophagus lycimnia outcompeted parasitoids of the genus Metaphycus when parasitizing S. oleae nymphs. Our analyses were primarily designed to detect the mechanism and effects of competition on host exploitation by both parasitoid genera and the density of their common host. Although parasitism rates were very low at the beginning of the scale life cycle (September), our data suggest that scale mortality is positively related to the parasitism rates of $C$. lycimnia during this season, while independent of Metaphycus parasitism during the same season. Therefore, C. lycimnia reduced the population of soft scales independently of the primary parasitoids of the genus Metaphycus. Later on, in May, parasitism rates by the autoparasitoid reached almost $30 \%$. Theory predicts that pest suppression will be disrupted except when primary parasitoids and autoparasitoids are equally effective at suppressing the pest (Briggs \& Collier, 2001). Our results are in disagreement with this prediction because, although $C$. lycimnia uses hosts later in their development (i.e. of larger size) than do parasitoids of the Metaphycus genus, we found the autoparasitoid to be bmore efficient than the primary parasitoids in suppressing $S$. oleae in northern Portugal olive trees.

Two previous studies addressed the effects of competition between primary and autoparasitoids on the population of a common host, though in field cages (Bográn et al., 2002; Hunter et al., 2002). Our work differs with previous studies in the literature in that natural populations in their natural environment were used. The two previous studies are based on the use of caged plants and the subsequent release of parasitoids. This methodology allowed host population densities to be compared when parasitoids were absent, released alone, or in competition, so that their effect could be determined. However, this inoculative methodology did not consider the dynamic phenology of the distinct species (i.e. different arrival times within the season, so mixtures of host and parasitoid ages, etc.) as well as their dispersal from other patches (i.e. metapopulation dynamics). The arrival and attack of the distinct species might differ according to the phenology of the host and their climatic necessities, as well as other factors such as alternative hosts, surrounding vegetation, margins, etc. (Snyder et al., 2005). In fact, metapopulation dynamics may account 
for the persistence and success of biological control in systems (Murdoch et al., 1996). In our study, three different Metaphycus species were found, and they differed in their host exploitation strategies (particularly M. lounsburyi). This result emphasises the importance of analysing changes in the metacommunity when exploring the success or failure of biological control programmes.

Metaphycus species are usually considered superior competitors and more effective biological control agents than C. lycimnia because they can outcompete the autoparasitoid through exploitative competition using hosts of smaller size (Bernal et al., 2001; Kapranas et al., 2007; Tena \& Garcia-Marí, 2008; Kapranas \& Tena, 2015; herein). The exploitation of smaller hosts by parasitoids of whiteflies and scale insects (including armoured scales, soft scales and mealybugs) is a widely documented mechanism that explains the superiority of the primary parasitoids and sometimes the displacement of competitor parasitoids that need larger hosts to develop (Luck $\&$ Podoler, 1985). In our study, however, we found the opposite, as $C$. lycimnia was the stronger competitor, with clearer impacts on pest suppression compared with the primary parasitoids. Metaphycus flavus and M. helvolus used smaller hosts than $C$. lycimnia; however, this preemptive resource exploitation did not permit them to outcompete $C$. lycimnia.

Size-mediated antagonistic interactions can allow competing species to coexist. Recently, we demonstrated this with the primary parasitoids Aphytis melinus DeBach and Aphytis chrysomphali (Hymenoptera: Aphelinidae) (Pekas et al., 2016). These parasitoids can coexist when they parasitise the armoured scale Aonidiella aurantii (Maskell) (Hemiptera: Diaspididae), because the weaker competitor (A. chrysomphali) survives on smaller hosts when the density of the superior competitor (A. melinus) is high. This host exploitation pattern provides the poorer competitor with an competition-free space. In our study, however, we could not observe this coexistence mechanism because the poorer competitor, Metaphycus, did not use smaller hosts when $C$. lycimnia parasitism was high. This was revealed by non-significant interactions between host size and host exploitation by C. lycimnia on the parasitism rates of Metaphycus. Similarly, Bográn et al. (2002) found the primary parasitoid E. mundus to use smaller hosts in the presence of the autoparasitoid E. pergandiella than when released alone. On the other hand, the significant interaction between host size and host exploitation by Metaphycus on parasitism by $C$. lycimnia suggests that the autoparasitoid might change its host exploitation pattern depending on Metaphycus density. This potential change in host exploitation might also explain why Metaphycus parasitism did not recover later in the life cycle of its host.

Our results also provide insights into other potential mechanisms and potential life-history strategies that allow C. lycimnia to outcompete Metaphycus parasitoids. First, C. lycimnia had a higher proportion of females than Metaphycus in the three studied seasons. In addition, the secondary sex ratio varied with antagonistic interactions, as the proportion of females did not increase with host size when Metaphycus host exploitation increased in November. As C. lycimnia is a facultative autoparasitoid, this result suggests that $C$. lycimnia might prefer to use Metaphycus females rather than their own females as a secondary host to produce males. Such host preference would provide $C$. lycimnia with a substantial competitive advantage over Metaphycus parasitoids, which may partially explain why the mortality of the host throughout the study was independent of Metaphycus parasitism when C. lycimnia levels were high. Zang et al. (2011) found that Encarsia sophia, an autoparasitoid of whiteflies, also prefers to use heterospecific hosts as secondary hosts for producing males in a choice test in the laboratory. This preference could be due to the higher fitness of males developed on heterospecific females as compared with those developed on conspecific ones (Zang et al., 2011). Bernal et al. (2001) also encountered a positive relationship between the numbers of Metaphycus and the proportion of C. lycimnia males in field conditions when parasitizing the soft scale, $C$. pseudomagnoliarum. Nevertheless, the authors suggested that the high population densities of C. lycimnia might reduce the density of Metaphycus species and explain the negligible control of citricola scale in California's San Joaquin Valley (Bernal et al., 2001).

\section{Conclusions}

Herbivore suppression may depend on intricate interactions among multiple parasitoid species that have important implications for pest regulation. This is particularly true for species with uncommon life-history strategies, such as autoparasitoids. In the case of soft scales, such as $S$. oleae, they are generally controlled by a complex of primary parasitoids of the family Encyrtidae, which are attacked by autoparasitoids of genus Coccophagus (Kapranas \& Tena, 2015). As Coccophagus spp. can negatively influence the population dynamics of their encyrtid hosts, their use in biological control programmes has been limited. However, our data show that $C$. lycimnia, an autoparasitoid that is inferior at resource exploitation, outcompeted the complex of primary parasitoids of the genus Metaphycus and regulated the population of their common host, $S$. oleae, in olive trees from Portugal. Therefore, the role of $C$. lycimnia as a biological control agent of soft scales should be reconsidered in future biological control programmes. Finally, our study will also contribute to understanding how autoparasitoids may outcompete primary parasitoids and affect the outcome of biological control efforts in agriculture.

\section{Acknowledgements}

We are grateful to Dr Jay Rosenheim and Dr Apostolos Kapranas for their helpful comments one a previous version of this manuscript, and three anonymous reviewers for their detailed review of the current version. The authors declare there are no conflicts of interest.

\section{Supporting Information}

Additional supporting information may be found online in the Supporting Information section at the end of the article.

Appendix S1. Saissetia oleae size and its effect on parasitoid exploitation and sex ratio. 


\section{References}

Bates, D., Maechler, M., Bolker, B. \& Walker, S. (2014) lme4: Linear mixed-effects models using Eigen and S4. R package, version 1.1-7. http://CRAN.R-project.org/package=lme4.

Ben-Dov, Y. \& Hodgson, C.J. (1997) Soft Scale Insects: Their Biology, Natural Enemies and Control. Elsevier Science B.V, Amsterdam, the Netherlands.

Bernal, J.S., Luck, R.F. \& Morse, J.G. (1998) Sex ratios in field populations of two parasitoids (hymenoptera: Chalcidoidea) of Coccus hesperidum L. (Homoptera: Coccidae). Oecologia, 116, 510-518.

Bernal, J.S., Luck, R.F. \& Morse, J.G. (1999) Augmentative release trials with Metaphycus spp. (hymenoptera: Encyrtidae) against citricola scale (Homoptera: Coccidae) in California's San Joaquin Valley. Journal of Economic Entomology, 92, 1099-1107. https://doi.org/10 .1093/jee/92.5.1099.

Bernal, J.S., Luck, R.F., Morse, J.G. \& Drury, M.S. (2001) Seasonal and scale size relationships between citricola scale (Homoptera: Coccidae) and its parasitoid complex (hymenoptera: Chalcidoidea) on San Joaquin Valley citrus. Biological Control, 20, 210-221.

Bográn, C.E., Heinz, K.M. \& Ciomperlik, M.A. (2002) Interspecific competition among insect parasitoids: field experiments with whiteflies as hosts in cotton. Ecology, 83, 653-668.

Boivin, G. \& Brodeur, J. (2006) Intra- and Interspecific Interactions Among Parasitoids: Mechanisms, Outcomes and Biological Control. Trophic and Guild Interactions in Biological Control (pp. 123-144). Springer, Dordrecht, the Netherlands.

Borer, E.T., Briggs, C.J., Murdoch, W.W. \& Swarbrick, S.L. (2003) Testing intraguild predation theory in a field system: does numerical dominance shift along a gradient of productivity? Ecology Letters, 6 , 929-935.

Borer, E.T., Murdoch, W.W. \& Swarbrick, S.L. (2004) Parasitoid coexistence: linking spatial field patterns with mechanism. Ecology, 85, 667-678. https://doi.org/10.1890/02-0566.

Briggs, C.J. (1993) Competition among parasitoid species on a stage-structured host and its effect on host suppression. American Naturalist, 141, 372-397.

Briggs, C.J. \& Collier, T.R. (2001) Autoparasitism, interference, and parasitoid-pest population dynamics. Theoretical Population Biology, 60, 33-57.

De Bach, P. (1943) The importance of host-feeding by adult parasites in the reduction of host populations. Journal of Economic Entomology, 36, 647-658.

Flanders, S.E. (1942) Metaphycus helvolus, an encyrtid parasite of the black scale. Journal of Economic Entomology, 35, 690-698.

Frago, E. (2016) Interactions between parasitoids and higher order natural enemies: intraguild predation and hyperparasitoids. Current Opinion in Insect Science, 14, 81-86.

Goulet, H. \& Hulent, H.F. (1993) Hymenoptera of the World: An Identification Guide to Families. Research Branch, Agricultural. Canada Publication Canada Communication. Group Publishing, Ottawa, Canada.

Guerrieri, E. \& Noyes, J.S. (2000) Revision of european species of genus Metaphycus Mercet (hymenoptera: Chalcidoidea: Encyrtidae), parasitoids of scale insects (Homoptera: Coccoidea). Systematic Entomology, 25, 147-222. https://doi.org/10.1046/j.1365-3113.2000 .00099.x.

Hunter, M.S. \& Woolley, J.B. (2001) Evolution and behavioural ecology of heteronomous aphelinid parasitoids. Annual Review of Entomology, 46, 251-290.

Hunter, M.S., Collier, T.R. \& Kelly, S.E. (2002) Does an autoparasitoid disrupt host suppression provided by a primary parasitoid? Ecology, 83, 1459-1469.
Janssen, A., Montserrat, M., HilleRisLambers, R., Roos, A.M., Pallini, A. \& Sabelis, M.W. (2006) Intraguild predation usually does not disrupt biological control (pp. 21-44). Trophic and Guild in Biological Interactions Control. Springer, Dordrecht, the Netherlands.

Kapranas, A. \& Luck, R.F. (2008) Egg maturation, host feeding, and longevity in two Metaphycus species parasitoids of soft scale insects. Biological Control, 47, 147-153.

Kapranas, A. \& Tena, A. (2015) Encyrtid parasitoids of soft scale insects: biology, behaviour and their use in biological control. Annual Review of Entomology, 60, 195-211.

Kapranas, A., Morse, J.G., Pacheco, P., Forster, L.D. \& Luck, R.F. (2007) Survey of brown soft scale Coccus hesperidum L. parasitoids in southern California citrus. Biological Control, 42, 288-299.

Luck, R.F. \& Podoler, H. (1985) Competitive exclusion of Aphytis lingnanensis by A. melinus: potential role of host size. Ecology, 66 , 904-913.

Manly, B.F.J., Mcdonald, L., Thomas, D.L., Mcdonald, T.L. \& Erickson, W.P. (2002) Resource Selection by Animals: Statistical Design and Analysis for Field Studies. Cambridge University Press, Kluwer Academic Publishers, Dordrecht, the Netherlands.

May, R.M. \& Hassell, M.P. (1981) The dynamics of multiparasitoid-host interactins. Americam Naturalist, 117, 234-261.

Muegge, M.A. \& Lambdin, P.L. (1989) Longevity and fecundity of Coccophagus lycimnia (walker) (hymenoptera: Aphelinidae), a primary parasitoid of Coccus hesperjdum (Homoptera: Coccidae). Journal of Agricultural Entomology, 6, 169-174.

Murdoch, W.W., Chesson, J., \& Chesson, P.L. (1985) Biological control in theory and practice. The American Naturalist, 125, 344-366.

Murdoch, W.W., Swarbrick, S.L., Luck, R.F., Walde, S. \& Yu, D.S. (1996) Refuge dynamics and metapopulation dynamics: an experimental test. The American Naturalist, 147, 424-444.

Pekas, A., Tena, A., Harvey, J.A., Garcia-Marí, F. \& Frango, E. (2016) Host size and spatiotemporal patterns mediate coexistence of specialist parasitoids. Ecology, 97, 1345-1356.

Pereira, J.A.C. (2004) Bioecologia da cochonilha negra Saissetia oleae (Olivier), na oliveira, em Trás-os-Montes. PhD dissertation, Universidade de Trás-os-Montes e alto Douro, Vila Real.

Polis, G.A., Myers, C.A. \& Holt, R.D. (1989) The ecology and evolution of the intraguild predation - potential competitors that eat each other. Annual Review of Ecology and Systematics, 20, 297-330.

Rosenheim, J.A. (1998) Higher-order predators and the regulation of insect herbivore populations. Annual Review of Entomology, 43, 421-447.

Rosenheim, J.A., Kaya, H.K., Ehler, L.E., Marois, J.J. \& Jaffee, B.A. (1995) Interguild predation among biological- control agents: theory and evidence. Biological Control, 5, 303-335.

Schweizer, H., Morse, J.G., Luck, R.F. \& Forster, L.D. (2002) Augmentative releases of a parasitoid (Metaphycus sp. nr. flavus) against citricola scale (Coccus pseudomagnoliarum) on oranges in the San Joaquin Valley of California. Biological Control, 24, 153-166.

Schweizer, H., Luck, R.F. \& Morse, J.G. (2003) Augmentative releases of Metaphycus sp. nr. flavus against citricola scale on oranges in the San Joaquin Valley of California: are early releases better than late ones? Journal of Agricultural Entomology, 96, 1375-1387.

Snyder, W.E. \& Ives, A.R. (2008) Behaviour influences whether intra-guild predation disrupts herbivore suppression by parasitoids. Behavioural Ecology of Insect Parasitoids (ed. by E. Wajnberg, C. Bernstein and J. van Alphen), pp. 71-91. Blackwell Press, Oxford, U.K.

Snyder, R.E., Borer, E.T. \& Chesson, P. (2005) Examining the relative importance of spatial and nonspatial coexistence mechanisms. The American Naturalist, 166, 75-94.

Tena, A. \& Garcia-Marí, F. (2008) Suitability of citricola scale Coccus pseudomagnoliarum (Hemiptera: Coccidae) as host of Metaphycus 
helvolus (hymenoptera: Encyrtidae): influence of host size and encapsulation. Biological Control, 46, 341-347.

Tena, A. \& Garcia-Marí, F. (2009) Brood size, sex ratio and egg load of Metaphycus lounsburyi (hymenoptera: Encyrtidae) when parasitizing adult females of black scale Saissetia oleae (Hemiptera: Coccidae) in the field. Biological Control, 51, 110-115.

Tena, A., Soto, A., Vercher, R. \& Garcia-Marí, F. (2007) Density and structure of Saissetia oleae (Hemiptera: Coccidae) populations on citrus and olives: relative importance of the two annual generations. Environmental Entomology, 36, 700-706.

Tena, A., Soto, A. \& Garcia-Marí, F. (2008a) Parasitoid complex of black scale Saissetia oleae on citrus and olives: parasitoid species composition and seasonal trend. BioControl, 53, 73-487.
Tena, A., Kapranas, A., Garcia-Marí, F. \& Luck, R.F. (2008b) Host discrimination, superparasitism and infanticide by a gregarious endoparasitoid. Animal Behaviour, 76, 789-799.

Tougeron, K. \& Tena, A. (2019) Hyperparasitoids as new targets in biological control in a global change context. Biological Control, $\mathbf{1 3 0}$, $164-171$.

Zang, L.S., Liu, T.X. \& Wan, F.H. (2011) Reevaluation of the value of Autoparasitoids in biological control. PLoS One, 6, e20324.

Accepted 16 January 2020

Associate Editor: Saskya van Nouhuys 